\title{
Documentation and Communication of Psychooncological Findings in an Interdisciplinary Breast Cancer Center
}

\author{
Anne Grimm ${ }^{a, b} \quad$ Barbara Voigt ${ }^{a, b} \quad$ Petra Georgiewa ${ }^{a, b} \quad$ Thomas Fydrich $^{c} \quad$ Dieter Kleiber $^{d}$ \\ Burghard F. Klapp ${ }^{a}$ Martina Rauchfuß ${ }^{a, b}$ \\ ${ }^{a}$ Medizinische Klinik mit Schwerpunkt Psychosomatik, \\ ${ }^{\mathrm{b}}$ Brustzentrum, Charité - Universitätsmedizin Berlin, \\ c Psychotherapie und Somatopsychologie, Institut für Psychologie, Humboldt-Universität zu Berlin, \\ ${ }^{d}$ Public Health: Prävention und psychosoziale Gesundheitsforschung, Erziehungswissenschaft und Psychologie, Freie Universität Berlin, \\ Germany
}

\section{Key Words}

Breast cancer - Breast Cancer Center .

Psychooncological findings · Psychooncological inpatient treatment $\cdot$ Psychooncological evaluation

\section{Summary}

Background: Psychooncological interventions are an integral component of the treatment of breast cancer patients in certified breast cancer centers. Effective multidisciplinary care requires excellent communication among the team members, including written communication. The study explores how written communication can be implemented in a multidisciplinary team treating cancer patients. Patients and Methods: A computerized form to enter psychooncological findings into a software designed for the documentation of the diagnostics and therapy of patients with breast cancer was developed. Results: The psychooncological module includes the sections phase of therapy, mood disturbances, difficulties in handling the disease/treatment, psychosocial burdens, psychosocial resources and treatment recommendations as well as notes about a psychological diagnosis (International Classification of Diseases (ICD)-10) where appropriate. 555 psychooncological findings were documented in the newly designed module. $28 \%$ of the patients were diagnosed with a mental disorder. $45 \%$ received at least one intervention. Conclusions: The psychooncological module facilitates the combination of oncological and psychooncological documentation. It can give structured psychooncological information to the physicians. However, the development of the module has to be continued.

\author{
Schlüsselwörter \\ Brustkrebs · Brustzentrum - Psychoonkologische Befunde . \\ Psychoonkologische, stationäre Behandlung . \\ Psychoonkologische Einschätzung
}

\section{Zusammenfassung}

Hintergrund: Psychoonkologische Versorgung ist ein integraler Bestandteil der Behandlung in einem zertifizierten Brustzentrum. Erfolgreiche multidisziplinäre Versorgung erfordert ausgezeichnete Kommunikation zwischen den Teammitgliedern, insbesondere auch schriftliche Kommunikation. Die Studie stellt dar, wie ein schriftlicher Austausch in einem multidisziplinären Team umgesetzt werden kann. Patienten und Methoden: Für das im Brustzentrum der Charité eingesetzte Dokumentationssystem wurde ein Formular zur Eingabe psychoonkologischer Befunde entwickelt. Ergebnisse: Das Psychoonkologie-Modul ist gegliedert in die Kategorien Therapiephase, Stimmung, Krankheitsbewältigung, psychosoziale Belastungen, psychosoziale Ressourcen und Weiterbehandlungsempfehlungen sowie gegebenenfalls Anmerkungen zu psychischen Diagnosen (Internationale Klassifikation der Krankheiten 10 (ICD-10)). 555 psychoonkologische Befunde wurden in dem neu entwickelten Modul dokumentiert. Bei 28\% der Patienten wurde eine psychische Erkrankung diagnostiziert. 45\% der Patienten erhielten mindestens eine Intervention. Schlussfolgerungen: Das vorgestellte computergestützte Psychoonkologie-Modul ermöglicht eine Verbindung zwischen onkologischer und psychoonkologischer Dokumentation. Es kann strukturierte Informationen an die behandelnden Ärzte vermitteln, muss jedoch in einigen Punkten überarbeitet werden.

\begin{tabular}{ll}
\hline KARGER & @ 2009 S. Karger GmbH, Freiburg \\
Fax +49 7614520714 & Accessible online at: \\
Information@Karger.de & www.karger.com/brc \\
www.karger.com &
\end{tabular}

Dipl.-Psych. Anne Grimm

Med. Klinik mit Schwerpunkt Psychosomatik

Charité - Universitätsmedizin Berlin

Luisenstr. 13a, 10117 Berlin, Germany

Tel. +49 30 450553-123, Fax -989

anne.grimm@charite.de 


\section{Introduction}

Although psychological problems are common in people with cancer, they are frequently underrecognized and undertreated [1]. In a certified breast cancer center, psychooncological diagnostics and interventions have to be an integral component of the treatment of patients $[2,3]$. Psychooncological care includes information and psychoeducation of the patients and monitoring of the emotional and psychological impact of the cancer on the patients. Furthermore, psychooncological interventions should be offered in close temporal proximity to the patients' needs and the continuity of care after discharge should be ensured [4].

To fulfil these criteria, practitioners trained and skilled in psychooncological care are required. A multidisciplinary team treatment of cancer patients is recommended [5, 6]. In the Charité, the Department of Psychosomatic Medicine offers the patients of the breast cancer center psychooncological diagnostics and treatment as an integral health care module $[7,8]$. The cooperation makes it possible to use existing structures in the psychosomatic department. These established structures of the psychosomatic department are team supervision, further care of the patient on an outpatient basis, and psychooncological crisis management in the sense of a 24-h psychosomatic standby service. Furthermore, the patient can be admitted to the psychosomatic ward, if required. In contrast to having a psychooncologist who is directly assigned to the gynecological clinic, the breast cancer center in the Charité finances partial positions for colleagues of the psychosomatic department. The psychooncological care of the patients is consequently not carried out by a single individual, but rather by a team made up of psychologists and physicians.
Effective multidisciplinary care requires excellent communication among the team members, including written communication [9]. To ensure the continuity of care after discharge, a comprehensive documentation of the psychooncological findings and their disclosure is necessary.

The aim of the study is to describe how written communication can be implemented in a multidisciplinary team treatment of cancer patients from a psychooncological perspective.

\section{Method}

A module to enter psychooncological findings into a software designed for the documentation of the diagnostics and therapy of patients with breast cancer (ODSeasy ${ }^{\circledR}$, Asthenis GmbH, Munich, Germany) was developed. A workgroup composed of 3 psychologists (1 with finished psychotherapy qualification) and 1 gynecologist and psychotherapist was formed, all of whom are trained in psychooncological care. The team discusses the pressing psychosocial problems of the breast cancer inpatients in close temporal proximity to a surgery. The team members have educated themselves more broadly about psychooncological guidelines and the Basic Documentation for Psycho-Oncology (PO-Bado) [4, $10,11]$. Over a 5 -month period, weekly 10-min discussions and two 1-h meetings were held. In order to sample perspectives and to benefit from the experience of colleagues with other specializations, an oncologist and a breast care nurse were contacted. They were interviewed and the breast care nurse took part in one of the discussions. The first version of the module was used by the team members and the oncologist as well as the breast care nurse for the evaluation of 10 patients in each case. Proposed modification options were discussed in the team meetings. The actual version of the psychooncological module was technically implemented in September 2007 by Asthenis.

The diagnosis of the breast cancer patients treated from September 2007 to the end of 2008 and the psychooncological interventions given in 2007/2008 were recorded in the documentation system of the Department of Psychosomatic Medicine (PsomDok ${ }^{\circledR}$ ).
Fig. 1. Integration of psychooncological care into the oncological treatment routine.

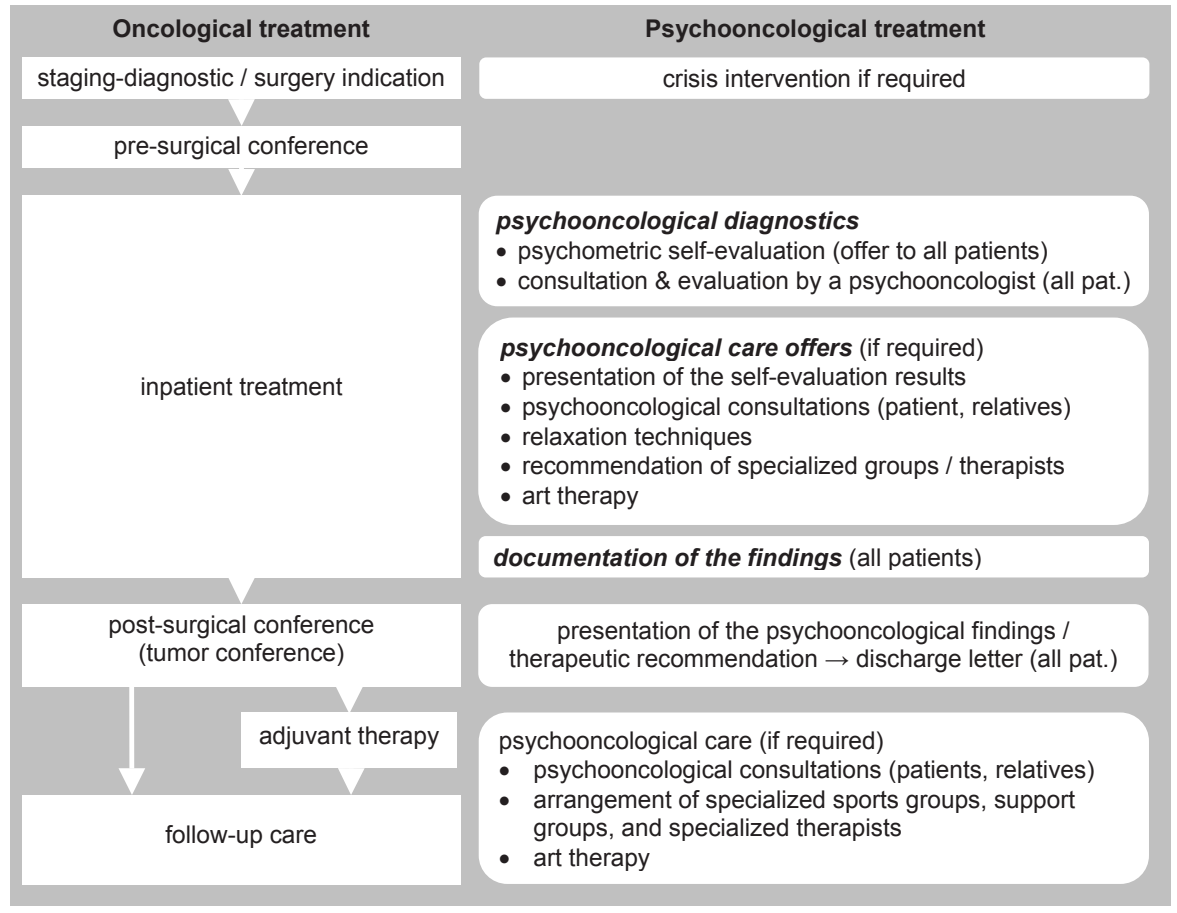




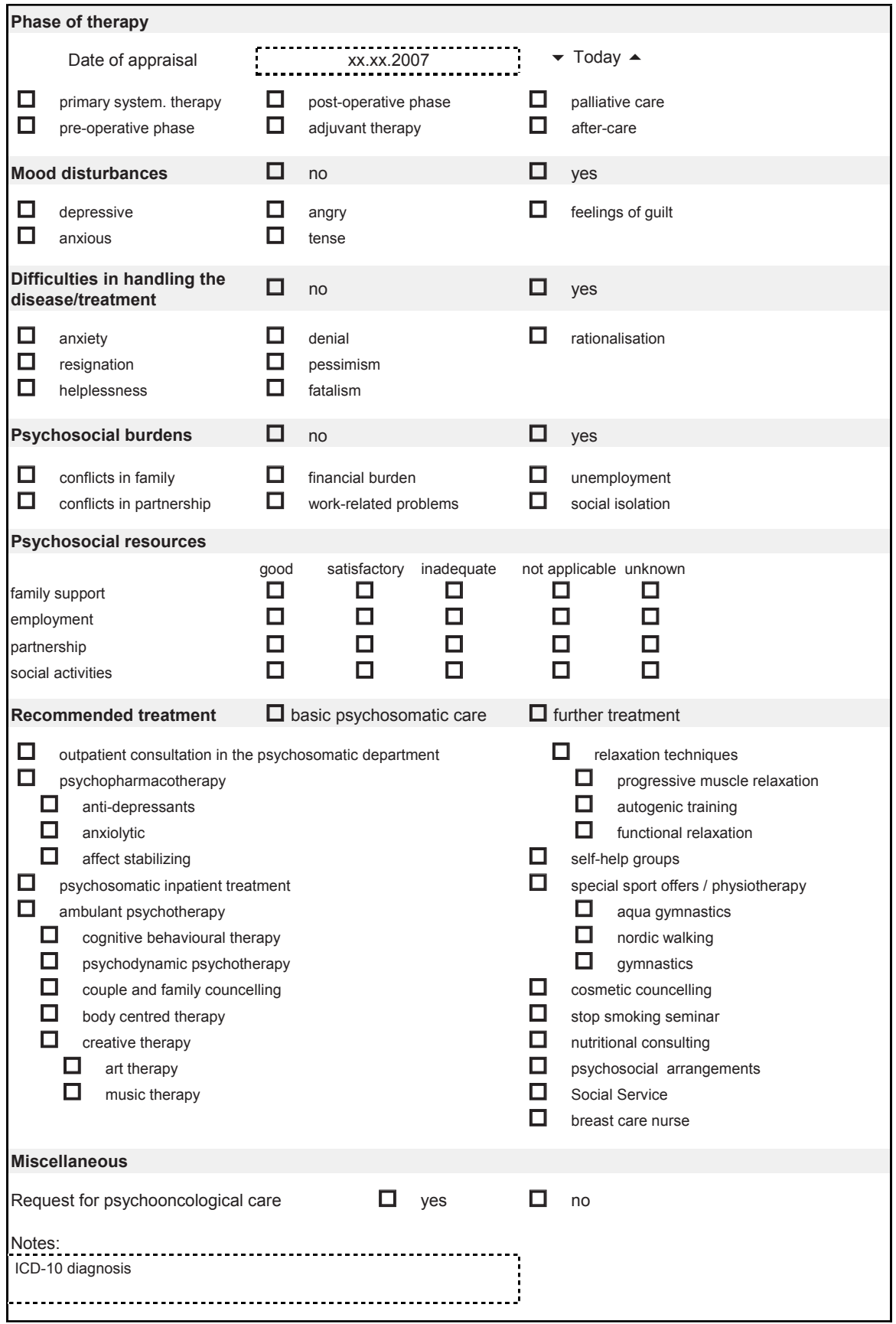

Fig. 2. The psychooncological module in ODSeasy $^{\circledR}$.

\section{Results}

Figure 1 shows how psychooncological care is integrated into the oncological treatment routine in the Charité. On the day of admission, all patients are contacted by colleagues of the psychosomatic department. At first contact, the patients are informed about the psychosocial aspects of the disease and the available psychooncological offers (fig. 1). A flyer with information is handed out.

To get a global evaluation of the mental state of the breast cancer patients, we assess a psychooncologist's evaluation of each patient, and, in addition, a self-evaluation with a set of psychometric instruments is offered to the patients. The computerized entry of the self-evaluation data via personal digital assistant (PDA) by the patients makes it possible to interpret and discuss the results with the patients almost immediately [12]. The individual data of a patient are automatically presented in graphics in comparison to data of psychosomatic patient samples or non-clinical samples.

For each contact with the patient, the psychooncologist fills in a paper pencil form of the ODSeasy module. In the majority of cases, the computerized documentation in ODSeasy is based on two of these paper pencil forms. Filling in the form takes about 3-4 min. Transferring the data into the compu- 
terized module takes another 2-3 min. Figure 2 shows the psychooncological module with the sections phase of therapy, mood disturbances, difficulties in handling the disease/treatment, psychosocial burdens, psychosocial resources and treatment recommendations as well as their corresponding subcategories. If none of the subcategories in one section is checked, the section collapses. In this way, it is possible to differentiate between 'positive' and 'no abnormalities detected' findings at a glance.

The psychooncological findings recorded in ODSeasy can be accessed at all workplaces in the breast cancer center of the Charité. They are an integral component of the patient documentation and are presented along with the somatic findings for each patient. The psychooncological findings are also presented in the weekly interdisciplinary conference of the breast cancer center, in which the further treatment of all treated patients in the last week is discussed and its results are recorded. Less structured interdisciplinary exchange concerning the psychosocial situation of the patients takes place in short discussions between psychologists, physicians and health care personnel (especially the breast care nurse [13]), and during the ward rounds in which a psychooncologist from the psychosomatic department participates once a week.

From the implementation of the psychooncological module in ODSeasy in September 2007 until the end of 2008, the psychooncological findings of 555 patients were documented. The average age of the women was 59.5 years (standard deviation $(\mathrm{SD})=12.4$; ranging from 26 to 95 years).

About one quarter of the patients whose findings were documented in the psychooncological module 2007/2008 were diagnosed to be suffering from a mental disorder according to the International Classification of Disease (ICD)-10 ( $\mathrm{n}=154$ $28 \%$ ) [14]. When indicated, the psychooncologist diagnoses a mental disorder after conferring with the colleagues in the weekly psychooncological team meeting. Thus, the diagnosis is confirmed by at least two psychooncologists. The diagnosis is documented in the last section of the psychooncological module. Acute stress disorders and adjustment disorders represented $84 \%$ of the diagnoses made $(n=130)$. A further $6 \%$ $(\mathrm{n}=10)$ were attributed to mood disorders. The remaining 14 diagnoses were made up of anxiety disorders, drug dependency, psychoses and 1 personality disorder.

During their inpatient treatment (generally over the course of 4 days), psychooncological consultations can be carried out with the patients in close temporal proximity to their needs. Furthermore, the patients are offered ambulatory follow-up or, in the event that the need for such is to be observed, it is recommended explicitly. 249 of the 555 inpatient (45\%) received at least one intervention (10-20min consultations) beyond the first contact. An outpatient consultation in the psychosomatic department was recommended to 170 patients (31\%). Further recommendations include ambulant psychotherapy $(n=36 ; 6 \%)$, psychopharma- cotherapy $(\mathrm{n}=29 ; 5 \%)$ and admission to the psychosomatic ward $(\mathrm{n}=3 ; 0.5 \%) .235$ patients received addresses of selfhelp groups and 239 patients received addresses of special sports offers.

\section{Discussion}

The aim of the study is to describe how written computerized communication can be implemented in a multidisciplinary team treatment of cancer patients. A module to enter psychooncological findings into a software designed for the documentation of the diagnostics and therapy of patients with breast cancer was developed.

The presented module was implemented to routinely associate psychooncological aspects with an oncological treatment setting. The physicians have access to structured written information about psychooncological aspects at a glance. The presentation of the psychooncological findings by a psychooncologist at the interdisciplinary conference enables to integrate the psychooncological findings directly into the decisions concerning further treatment. To ensure continuity of care after discharge from our department, we try to send the psychooncological findings and recommendations for further treatment in physician letters to the doctors providing further care. We do not receive information on whether and which treatment recommendations are realized.

The module is not evaluated in a multi-center trial. Instead, only members of one team are included in the development process. First and foremost, the attribution of the subcategories to the superordinated sections, e.g. tense is assigned to mood, has to be reconsidered. In the course of the development of the psychooncological module, we decided not to include categories for body image concerns and sexual difficulties. These aspects were not considered to be relevant enough in the acute phase of inpatient treatment. This decision is to be carefully reconsidered. Thus, the development of the psychooncological module has to be continued.

If only one quarter of the patients with breast cancer demonstrate mental symptoms that conform to the criteria of a mental disorder listed in ICD-10, the question arises concerning the necessity of making contact with all inpatients. The goal of this procedure is to make an early, systematic and specialist identification of the psychooncological requirements in order to avoid the development of chronifications and prolongations of hospital stays for patients with clinically relevant mental symptoms [15]. We assume that one or two short consultations and the offer of psychosocial support, if needed, already have a relieving effect on a portion of the patients. The relieving effect of a minimal intervention was confirmed by Jacobsen et al. [16] in a study dealing with training to relieve stress during chemotherapeutic treatment. Our concept pursues a preventive approach. Specialized psychological services early in the course of treatment may minimize 
the likelihood of the patients developing significant disorders [17]. Breitbart [18] postulates that prompt consultation is recommended when the mental state of a patient threatens to impede or complicate the treatment. Therefore trained personnel to offer prompt crisis intervention is required. A further chance for a therapeutic concept with a low-threshold design is dependent on providing information to all of the patients at an early point in time regarding the possible psychological complaints that might be associated with breast cancer. In the literature, it has been reported that the patients' anxiety can be reduced through psychoeducation and specialist information [19-21].

\section{Conclusions}

The psychooncological module is an effort to summarize the assessed psychooncological information and offer it to the physicians in a structured way. Furthermore, the module facilitates the combination of oncological and psychooncological documentation. However, the development of the psychooncological module has to be continued.

\section{Conflict of Interest}

All authors declare that there is no conflict of interest.

\section{References}

1 McDaniel JS, Musselman DL, Porter MR, Reed DA, Nemeroff CB: Depression in patients with cancer. Diagnosis, biology, and treatment. Arch Gen Psychiatry 1995;52:89-99.

2 Meyer A, Lehmann A, Schwarz R, Höckel M, Pilch $\mathrm{H}$ : Psychoonkologische Betreuung von Brustkrebspatientinnen: Erste Erfahrungen des zertifizierten universitären Brustzentrums Leipzig. Geburtsh Frauenheilk 2007;67:1339-1344.

3 Deutsche Krebsgesellschaft und Deutsche Gesellschaft für Senologie: Fachliche Anforderungen für die Zertifizierung von Brustzentren. www.dggg. de/_download/unprotected/zert_brust_anforderung. $p d f, 2006$.

4 Mehnert A, Petersen C, Koch U: Empfehlungen zur psychoonkologischen Versorgung im Akutkrankenhaus. Z Med Psychol 2003;12:77-84.

5 Luxford L, Rainbird K: Multidisciplinary care for women with breast cancer: A national demonstration program. N S W Public Health Bull 2001;12: 277-279.

6 Department of Health: The NHS Cancer Plan. Department of Health Publication, 2000.

7 Rauchfuß M, Blohmer JU, Neises M, Danzer G, Klapp BF: Psychoonkologische Versorgung in einem Brustzentrum. Geburtsh Frauenheilk 2004;64: $1158-1166$.

$>8$ Grimm A, Voigt B, Schneider A, Winzer KJ, Reißhauer A, Klapp BF, Rauchfuß M: Psychosoziale Befunde im Rahmen der psychoonkologischen Versorgung von Mammakarzinompatientinnen. Geburtsh Frauenheilk 2006;66:51-58.
9 National Breast Cancer Centre and the National Cancer Control Initiative: Clinical practice guidelines for the psychosocial care of adults with cancer. Camperdown, NSW, 2003.

10 Herschbach P, Book K, Brandl T, Keller M, Marten-Mittag B: The Basic Documentation for Psycho-Oncology (PO-Bado) - an expert rating scale for the psychosocial experience of cancer patients. Onkologie 2008;31:591-596.

11 Knight L, Mussell M, Brandl T, Herschbach P, Marten-Mittag B, Treiber M, Keller M: Development and psychometric evaluation of the Basic Documentation for Psycho-Oncology, a tool for standardized assessment of cancer patients. J Psychosom Res 2008;64:373-381.

12 Rose M, Hess V, Scholler G, Brähler E, Klapp BF: Mobile computergestützte psychometrische Diagnostik - Ökonomische Vorteile und Ergebnisse zur Teststabilität. Psychother Psychosom Med Psychol 1999;49:263-269.

13 Maguire P, Pitceathly C: Improving the psychological care of cancer patients and their relatives: The role of specialist nurses. J Psychosom Res 2003;55: 469-474.

14 WHO: International Classification of Diseases (ICD). www.who.int/classifications/icd/en, 2007.

15 Krauß O, Ernst J, Kuchenbecker D, Hinz A, Schwarz R: Prädiktoren psychischer Störungen bei Tumorpatienten: Empirische Befunde. Psychother Psychosom Med Psychol 2007;57:273-280.
6 Jacobsen PB, Meade CD, Stein KD, Chirikos TN, Small BJ, Ruckdeschel JC: Efficacy and costs of two forms of stress management training for cancer patients undergoing chemotherapy. J Clin Oncol 2002;20:2851-2862.

17 Sheard T, Maguire P: The effect of psychological interventions on anxiety and depression in oncology: results of two meta-analyses. New York, Third World Congress of Psycho-Oncology, 1996:3-6.

18 Breitbart W: Identifying patients at risk for, and treatment of major psychiatric complications of cancer. Support Care Cancer 1995;3:45-60.

19 Hawighorst-Knapstein S, Brueckner DO, Schoenefuss G, Knapstein PG, Koelbl H: Breast cancer care: Patient information and communication as a preventive educational process. Breast Care 2006;1: 375-378.

20 Devine EC, Westlake SK: The effects of psychoeducational care provided to adults with cancer: meta-analysis of 116 studies. Oncol Nurs Forum 1995;22:1369-1381.

21 Gündel H, Hümmeler V, Lordick F: Welche Tumorpatienten profitieren von einer interdisziplinären Psychoedukation im Rahmen der Tumortherapie? Z Psychosom Med Psychother 2007;53:324-338. 